\title{
Suppression of Insulin Aggregation by Heparin
}

\author{
Katie Giger, ${ }^{\dagger}$ Ram P. Vanam,${ }^{\ddagger}$ Emek Seyrek,${ }^{\perp}$ and Paul L. Dubin ${ }^{\star, \S}$ \\ Department of Chemistry, Indiana University-Purdue University at Indianapolis, 402 North Blackford Street, \\ Indianapolis, Indiana 46202
}

Received March 8, 2008; Revised Manuscript Received July 7, 2008

\begin{abstract}
The aggregation of insulin near its isoelectric point and at low ionic strength was suppressed in the presence of heparin. To understand this effect, we used turbidimetry and stopped-flow to study the $\mathrm{pH}$ - and ionic strength (I)-dependence of the aggregation of heparin-free insulin. The results supported the role of interprotein electrostatic interactions, contrary to the commonly held view that such forces are minimized at $\mathrm{pH}=\mathrm{pI}$. Electrostatic modeling of insulin (DelPhi) revealed that attractive interactions arise from the marked charge anisotropy of insulin near pI. We show how screening of the interprotein attractions by added salt lead to maximum aggregation near $I=$ $0.01 \mathrm{M}$, corresponding to a Debye length nearly equal to the diameter of the insulin dimer, consistent with a dipole-like protein charge distribution. This analysis is also consistent with suppression of aggregation by heparin, a strong polyanion that by binding to the positive domain of one protein, inhibits its interaction with the negative domain of another.
\end{abstract}

\section{Introduction}

Protein aggregation is of immense importance in a wide range of disciplines. One may assert that all proteins aggregate under some conditions, and a vast amount of research continues to disclose the variety of ways in which they do so. Of particular relevance is the understanding of neurodegenerative diseases such as Alzheimer's, Parkinson's, Huntington's, and CreutzfeldtJacobs disease, ${ }^{1}$ all of which have been associated with abnormal formation of protein aggregates or fibrils. Insulin is one of many proteins that undergo fibril formation ${ }^{2-4}$ and has been considered a model for amyloid formation, ${ }^{5}$ but its aggregation has also been studied in the context of pharmaceutical formulations. ${ }^{6,7}$ While insulin is most stable as a hexamer coordinated with 2-4 $\mathrm{Zn}$ atoms ${ }^{7}$ and is stored this way in the body, the size of the hexamer impedes absorption into the bloodstream. Therefore, insulin must be reduced to the less stable monomers and dimers for effective transport and activity. ${ }^{6}$ Both of these species tend to aggregate under a variety of conditions, posing a problem in the delivery of insulin for the treatment of diabetes. ${ }^{7}$ To maintain biological function, aggregates must either be dissociated or avoided completely, for example, through insulin analogs that have more stable monomers or dimers. ${ }^{6}$

We have noted that proteins aggregate in many ways; underlying part of this statement is the breadth of meanings attached to the word "aggregation". For this reason, it is useful to distinguish among "association", "aggregation", and "multimerization". The last term is most clearly defined by reference to the well-defined processes in which proteins form biofunctional and symmetrical assemblies (e.g., quaternary structure) via highly oriented short-range interactions. This distinction is particularly important in the case of insulin, where

* To whom correspondence should be addressed. E-mail: dubin@ chem.umass.edu.

' Current address: Department of Chemistry, Purdue University, W. Lafayette IN.

$\doteqdot$ Current address: Department of Biochemistry, Indiana University, Indianapolis IN.

${ }^{\S}$ Current address: Department of Chemistry, University of Massachusetts Amherst MA 01003.

${ }^{\perp}$ Current address: Institut Charles Sadron, Strasbourg, France. aggregation could result in oligomers containing $2,3,4$, and so forth dimers, the $n=3$ state not to be confused with the quaternary-structure hexamer formed with zinc. The terms "aggregation" and "association" are often used indiscriminately, but association is more commonly related to equilibrium states and aggregation more applicable to irreversible processes, often involving partial protein unfolding. Here, we confine the discussion of insulin aggregation to noncovalent and, hence, potentially reversible processes.

The aggregation of insulin has been explored by many techniques, including static and dynamic light scattering, ${ }^{8,9}$ calorimetry, ${ }^{10}$ atomic force microscopy, ${ }^{5}$ optical and confocal microscopy, ${ }^{11}$ scanning electron microscopy (ibid), infrared spectroscopy, ${ }^{12}$ and mass spectrometry. ${ }^{2}$ The conditions for these studies are often intended to correspond to either the shipping and handling of pharmaceutical insulin, involving heat- and agitation-induced aggregation, or to accelerated fibril formation, typically involving low $\mathrm{pH}$ and high temperature. The fibrils formed in these cases appear to be based on linear aggregates of insulin monomers, and the process is believed to involve multiple steps including nucleation by a partially unfolded monomer to form protofibrils, which may then either intertwine to form fibrils or undergo elongation and lateral growth through further addition of non-native monomers, ultimately leading to the large insoluble aggregates that are observed. ${ }^{2,13}$ This secondary heterogeneous aggregation appears to be involved in insulin amyloidosis, ${ }^{6}$ under accelerated conditions. ${ }^{2,3,14}$ Many studies address the aggregation of insulin at extreme conditions: $\mathrm{pH} 2$, elevated temperature, under agitation, and near hydrophobic surfaces, but conspicuously absent from these conditions is the aggregation of insulin at room temperature near its isoelectric point, $\mathrm{pH} 5.5$ (the closest report being Kadima et al. who studied insulin aggregation at $\mathrm{pH} 7.5$ and 10.5, in 10 and $100 \mathrm{mM} \mathrm{NaCl}^{15}$ ). In the $\mathrm{pH}$ range 3-8, it does appear that the predominant but relatively unstable monomers and dimers tend to form large aggregates in a manner highly dependent upon $\mathrm{pH}$ and ionic strength. While the dimerization of insulin clearly involves a strong hydrophobic contribution, ${ }^{16}$ stabilizing the dimer with respect to the monomer (monomer predominates only at very low concentrations), ${ }^{17,18}$ the forces involved in the further 
association of the zinc-free dimer have not been fully resolved. Because aggregation mechanisms vary with the experimental conditions, studies at extremes of $\mathrm{pH}$ or temperature might not fully explain the aggregation of insulin at physiological conditions, nor more generally at room temperature, low ionic strength $(I<100 \mathrm{mM} \mathrm{NaCl})$, at $\mathrm{pH}$ near $\mathrm{pI}$.

The purpose of the present study was to investigate this last form of aggregation, the so-called "isoelectric precipitation" of insulin ${ }^{19}$ at low $I$ and the effect on it of heparin, a highly charged biopolymer whose biological functions are intimately connected with its ability to bind biofunctionally numerous proteins. ${ }^{20,21}$ A member of the glycosaminoglycan family, heparin is composed of variable disaccharide units of uronic acid and glucosamine. The monosaccharides are sulfated to various extents and linked via $1 \rightarrow 4$ glycosidic bonds. ${ }^{21-23}$ Most common to porcine mucosal heparins (75\%) are disaccharide repeats of 2-Osulfated-iduronic acid and 6-O-sulfated, N-sulfated-glucosamine. ${ }^{23}$ The influence of heparin on protein aggregation is complicated. Calamai et al. reported that polyanions, including heparin, promote the aggregation of amyloidogenic proteins. ${ }^{24}$ $\operatorname{Raman}^{25}$ summarized evidence for the in vitro promotion by heparin of $\mathrm{A} \beta$ fibrils $^{26}$ and the stimulation by heparin of amyloid fibrils of $\alpha$-synuclein. ${ }^{27}$ On the other hand, Guzmán-Casado et al. concluded from calorimetry studies that heparin does not alter the native state of acidic fibroblast growth factor and does not induce protein oligomerization. ${ }^{28}$ Other workers reported even more benign effects. Middaugh et al. reported that heparin enhanced the thermal stability of human fibroblast growth factor 1 (FGF1) and protected it from low-pH unfolding ${ }^{29}$ and that it elevated the temperature of aggregation of keratinocyte growth factor, (KGF)-2, at near-physiological $\mathrm{pH}$ and $I .{ }^{30}$ Stabilization by heparin of human growth hormone with respect to interfacial denaturation was reported by Zamiri. ${ }^{31}$ Wen et al. observed that heparin and dextran sulfate stabilize both FGF and KGF by preferential binding to the native state, ${ }^{32}$ while Chong et al. found that heparin and other anionic polymers stabilize aFGF with respect to aggregation at elevated temperature and neutral $\mathrm{pH}^{33}$ The anionic polysaccharide dextran sulfate, a plausible heparin analog, is reported to protect bFGF from acid, heat, and proteolytic degradation, ${ }^{34}$ and is also said to protect ovalbumin from heat-induced aggregation at low $I .{ }^{35}$ Finally, and most globally, it has been suggested that relatively nonspecific, but high-affinity binding of proteins to many polyanions may be not only benign but significantly biofunctional. ${ }^{36}$ Therefore, it was of interest to see if heparin, the most highly charged biopolyanion, might play a similarly favorable role in the suppression of the aggregation of insulin. To investigate this phenomenon, aggregation in insulin and insulinheparin solutions was followed by turbidimetric titration and stopped flow measurements. These results, coupled with protein electrostatic modeling, lead to a model for insulin aggregation and its suppression by heparin under conditions of low salt and $|\mathrm{pH}-\mathrm{pI}|<2$.

\section{Experimental Section}

Materials. Zn-free insulin was a gift from Eli Lilly Corp, LY4100, Lot KG5-WEF-179. Heparin (nominal MW $14 \mathrm{kDa}$ ) was purchased from Sigma (Catalog No. H3393; Lot B 53104). The nominal MW of clinical heparin from porcine intestinal mucosa is routinely given as either $14 \mathrm{kDa}$ or within a range of $13.5-15 \mathrm{kDa}$; a more reliable result of $11 \mathrm{kDa}$ for the weight-average $\mathrm{MW}$ was obtained by light scattering. ${ }^{37} \mathrm{NaCl}, 0.1 \mathrm{~N} \mathrm{HCl}$, and $0.1 \mathrm{~N} \mathrm{NaOH}$ were from Fisher. All solutions were prepared using Milli-Q water (Millipore, Billerica, MA).

Methods. Turbidimetry. Insulin solutions $(0.1 \mathrm{~g} / \mathrm{L})$ were prepared in $\mathrm{NaCl}$ solutions of desired ionic strength. The $\mathrm{pH}$ was adjusted to 9 , under which condition insulin forms stable dimers ${ }^{38}$ and solutions were stirred for $30 \mathrm{~min}$ to ensure equilibration of protein prior to filtration with $0.22 \mu \mathrm{m}$ filters (Sartorius AG, Germany). Heparin solutions (1.0 and $0.02 \mathrm{~g} / \mathrm{L}$ ) were prepared at similar ionic strength and $\mathrm{pH}$. Turbidity measurements were performed using a Brinkman PC 800 probe colorimeter equipped with a $1 \mathrm{~cm}$ path length probe $(420 \mathrm{~nm})$, and set to $100 \%$ transmittance with Milli-Q water. Transmittance was monitored ( \pm 0.1 transmittance units) while the $\mathrm{pH}$ was adjusted from 9 to 3 with $0.1 \mathrm{~N} \mathrm{HCl}$, added in $30 \mathrm{~s}$ intervals. For most $\mathrm{pH}$ values, the new value was reached and became relatively stable within a few seconds. The true turbidity, $\tau$, is nearly linear with $\tau^{\prime} \equiv 100-\% T$ for $\% T>90$.

Solutions of insulin and heparin were prepared by mixing the two in $1: 1 \mathrm{v} / \mathrm{v}$ ratio resulting in final insulin and heparin concentrations of 0.1 and $0.01 \mathrm{~g} / \mathrm{L}$, respectively. Addition of heparin after aggregation was done with a small volume $(0.1 \mathrm{~mL})$ of a concentrated heparin solution $(1 \mathrm{~g} / \mathrm{L})$ such that the change in insulin concentration was negligible.

Stopped-Flow. Stopped-flow experiments were performed at room temperature $\left(23{ }^{\circ} \mathrm{C}\right)$ with a Hi-Tech Scientific SF-61SX2 kinetasyst stopped-flow spectrofluorimeter, equipped with a $75 \mathrm{~W}$ xenon lamp. All measurements were made in the absorbance mode at $420 \mathrm{~nm}$. A solution of insulin $0.2 \mathrm{~g} / \mathrm{L}$ at $\mathrm{pH} 9.0$ in the desired concentration of $\mathrm{NaCl}$ was mixed with an equal volume of $\mathrm{NaCl}$ solution containing the amount of acid calculated to bring the $\mathrm{pH}$ to 5.5 . The target $\mathrm{pH}$ was attained within a few seconds. The data were converted to $\tau^{\prime}=$ $100-\% T$ before analysis.

Computational Methods. Molecular modeling was done using DelPhi v98.0 (Molecular Simulations Inc.), where the electrostatic potential in and around the protein is calculated by nonlinear solution of Poisson-Boltzmann equation. The protein was placed in the center of a grid box with its largest dimension occupying $40 \%$ of the grid length. The resolution was set at 101 grid points per axis. The dielectric constants of the solvent and the protein were set to 80 and 2.5, respectively. Using the fractional charges for each charged amino acid residue, the electrostatic potential is then calculated at every point inside the grid box.

The charges of amino acid residues were determined using as a starting point the simple model put forward by Tanford: a sphericalsmeared-charge model in which the titration curve of a protein was considered as the superposition of the curves for each of the seven groups of amino acids. ${ }^{39} \mathrm{~A}$ form of the Henderson-Hasselbach equation was defined in which all ionizable groups in any one class are intrinsically equivalent: ${ }^{39,40}$

$$
\mathrm{pH}-\log \left(\frac{\alpha_{i}}{1-\alpha_{i}}\right)=\left(\mathrm{p} K_{\text {int }}\right)_{i}-0.868 w \bar{Z}
$$

where $\alpha_{\mathrm{i}}$ is the fractional dissociation for an amino acid in any given ionizable group $i, \mathrm{p} K_{\mathrm{int}}$ is an intrinsic dissociation constant characteristic of each group, and $\bar{Z}$ is the average net charge of the protein. Electrostatic interactions are accounted for by $0.868 w \bar{Z}$, with $w$ being essentially an empirical fitting parameter. Titration curves were thus first constructed using $\mathrm{w}$ values obtained by Tanford ${ }^{41}$ by interpolation with respect to ionic strength, in conjunction with $\mathrm{p} K_{\text {int }}$ values that represented approximately the mean of literature data. Then, the $\mathrm{p} K_{\mathrm{int}}$ value for each group was adjusted in the range of previously found values until the differences between calculated and experimental titration curves were minimized. Adjusted $\mathrm{p} K_{\text {int }}$ values (see Table 1) were then used along with eq 1 to calculate the charges of each ionizable group at the desired $\mathrm{pH}$ and $I$.

Eq 1 has been used extensively and successfully to interpret potentiometric titrations of globular proteins such as ovalbumin, serum albumins, ribonuclease, hemoglobin, and $\beta$-lactoglobulin. ${ }^{42}$ Winzor, however, has pointed out the following limitations of this approach: (1) presumption of uniform charge distribution, (2) neglect of the effects of ion binding, and (3) assumption of identical accessibility and independent behavior of all ionizable groups. ${ }^{43}$ For the present purposes, this approach facilitates quantitative visualization of the dipole-like nature of the charges on insulin. 
Table 1. Instrinsic Dissociation Constants of Titratable Groups in Insulin

\begin{tabular}{|c|c|c|c|c|c|c|}
\hline \multirow[b]{2}{*}{ type of group } & \multicolumn{2}{|c|}{ No. in group ${ }^{a}$} & \multirow[b]{2}{*}{ No. found from titration curve ${ }^{a}$} & \multirow[b]{2}{*}{$\mathrm{p} K_{\mathrm{int}}{ }^{a}$} & \multirow[b]{2}{*}{ No. in group ${ }^{b}$} & \multirow[b]{2}{*}{$\mathrm{p} K_{\mathrm{int}}^{\mathrm{c}}$} \\
\hline & Sanger & $\overline{\text { Craig }}$ & & & & \\
\hline$\alpha$-carboxyl & 4 & 4 & 12.5 & $3.6 \pm 0.3$ & 4 & 3.6 \\
\hline imidazole & 4 & 4 & 4 & $6.40(6.0)$ & 4 & 6.4 \\
\hline$\alpha$-amino & 4 & 4 & 4 & $7.45(7.2)$ & 4 & 7.9 \\
\hline$\varepsilon$-amino & 2 & 2 & 10 & $9.60 \pm 0.10$ & 2 & 9.6 \\
\hline phenolic & $\overline{8}$ & 8 & & & 8 & 9.6 \\
\hline
\end{tabular}

${ }^{a}$ Values from ref 36. ${ }^{b}$ Actual number in group, taken from RCSB Protein Data Bank (crystal structure 1ZNI). ${ }^{c}$ Best fit values (see text for explanation).

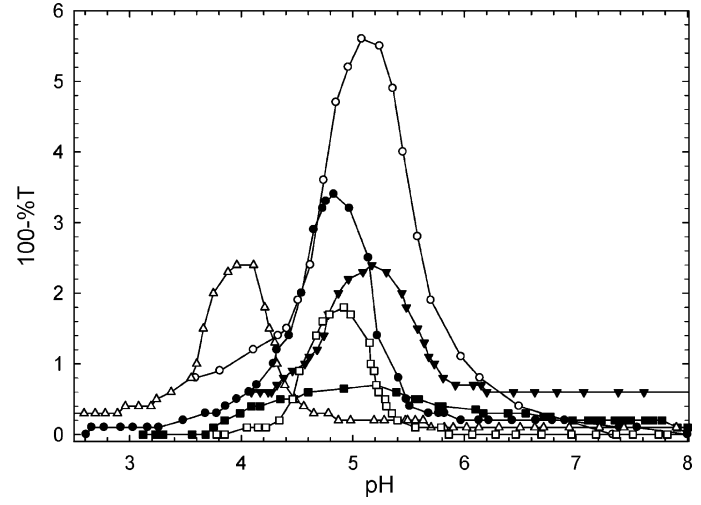

Figure 1. Turbidimetric titrations of $0.1 \mathrm{~g} / \mathrm{L}$ insulin in $0.5 \mathrm{mM}(\triangle), 1$ $\mathrm{mM}(\boldsymbol{\nabla}), 3 \mathrm{mM}(\square), 5 \mathrm{mM}(\bullet), 10 \mathrm{mM}(\mathrm{O})$, or $30 \mathrm{mM}(\boldsymbol{\square}) \mathrm{NaCl}$.

\section{Results}

Figure 1 shows the results of turbidimetric titrations in which $\mathrm{HCl}$ is added to $0.1 \mathrm{~g} / \mathrm{L}$ insulin at ionic strengths from 0.5 to 50 $\mathrm{mM}$. These results do not correspond to equilibrium states but, as will be shown below, reflect aggregation kinetics, although the asymptotically low turbidities at the $\mathrm{pH}$ extremes are consistent with the observation that for $<0.5 \mathrm{~g} / \mathrm{L}$ insulin, dimer is the stable form at $\mathrm{pH} 3.7$ and $\mathrm{pH} 8^{8}$ and at $\mathrm{pH} 9.3$. $^{38}$ From the titration curve of insulin ${ }^{41}$ one sees a linear relationship between the $\mathrm{pH}$ and the number of protons taken up by insulin, that is, constant $\left(\mathrm{dH}^{+} / \mathrm{dpH}\right)$, in the relevant $\mathrm{pH}$ range of $4-6.5$. The titration of water and heparin make negligible contributions compared to that of insulin so the uptake of $\mathrm{H}^{+}$by insulin can be identified with the rate of $\mathrm{H}^{+}$addition $\left(\mathrm{dH}^{+} / \mathrm{dV}_{\mathrm{HCl}}\right)$. Because $\left(\mathrm{dV}_{\mathrm{HCl}} / \mathrm{dt}\right)$ is constant, then $\mathrm{dpH} / \mathrm{dt}=\left(\mathrm{dV}_{\mathrm{HCl}} / \mathrm{dt}\right)\left(\mathrm{dH}^{+} / \mathrm{dV}_{\mathrm{HCl}}\right)\left(\mathrm{dH}^{+} / \mathrm{dpH}\right)^{-1}$ is also constant. Therefore, we can assume that the $\mathrm{pH}$ changes linearly with time in the $\mathrm{pH}$ range 4-6.5. As a consequence, the slopes of the curves $\left(\mathrm{d} \tau^{\prime} / \mathrm{dt}\right)_{\mathrm{pH}}$ are good approximations of the change of tubidity with respect to time $\left(\mathrm{d} \tau^{\prime} / \mathrm{dt}\right)_{\mathrm{pH}}$, a qualitative measure of the rate of aggregation. Thus the maximum aggregation rate was found at $I$ $=10 \mathrm{mM}$ and $\mathrm{pH} 5.6$, slightly above the pI of insulin (5.5), a result consistent with stopped-flow data (see below).

The curves are symmetrical around $\mathrm{pH}=5.0 \pm 0.2$ for all ionic strengths except the lowest, $0.5 \mathrm{mM}$. Peak positions (amplitudes and regions of maximum negative slope) coincide for ionic strengths of 30, 10 and $1 \mathrm{mM}$. For $30 \mathrm{mM}$, aggregation is strongly repressed consistent with data at high salt in Figure 2 . The peak height and the maximum aggregation rate at $I=$ $0.5 \mathrm{mM}$ are strongly shifted to lower $\mathrm{pH}$. This may suggest a different mechanism for aggregation at the lowest ionic strength, although we note that in this case contributions from the protein itself make the ionic strength difficult to define.

The maximum in turbidity due to aggregation near $10 \mathrm{mM}$ is not to be confused with minima in second virial coefficients for, for example, lysozyme and apoferritin, because those nonmonotonic salt effects, observed at ionic strengths above or

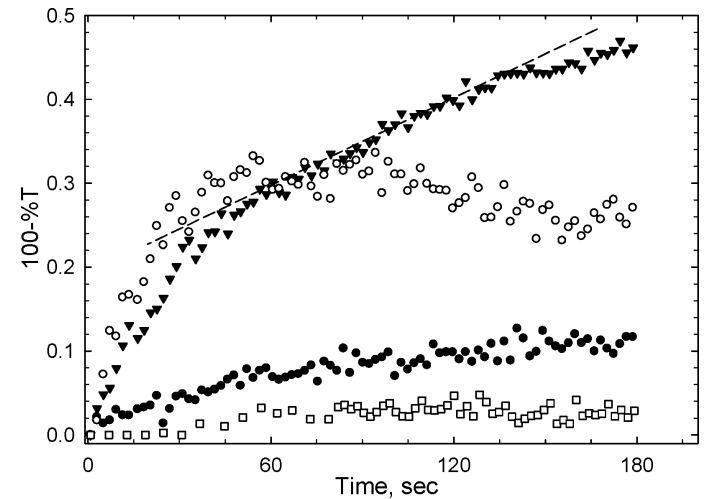

Figure 2. Turbidity vs time from stopped flow data for $0.1 \mathrm{~g} / \mathrm{L}$ insulin solutions at pH 5.5, with $2 \mathrm{mM}(\boldsymbol{\nabla}), 5 \mathrm{mM}(\bullet), 10 \mathrm{mM}(0)$, or $100 \mathrm{mM}$ $(\square) \mathrm{NaCl}$. Broken line (- - ) illustrates the transition between two modes of aggregation.

even much larger than $0.1 \mathrm{M},{ }^{44-47}$ are typically manifestations of very short-range interactions, such as dipole-dipole or solvation effects, and are often highly ion-specific. ${ }^{48}$ Here, the suppression of aggregation by the addition of salt (the opposite of "salting out") is strong evidence for electrostatically induced association, as seen for $\beta$-lactoglobulin at low ionic strength near its $\mathrm{pI} .{ }^{49}$ The maxima in the curves, $\left(\mathrm{d} \tau^{\prime} / \mathrm{dpH}\right) \approx\left(\mathrm{d} \tau^{\prime} / \mathrm{dt}\right)_{\mathrm{pH}}$ $=0$, correspond to the $\mathrm{pH}$ conditions at which rates of aggregation and disaggregation are equal, so that the aggregate accumulated up to that point neither increases nor decreases with time at fixed $\mathrm{pH}$. Holding the $\mathrm{pH}$ at this point in fact demonstrated no further change in turbidity (data not shown). The symmetry of the curves around this point indicates that deviations from $\mathrm{pH}_{\max }$ in either direction equally destabilize aggregates. This further suggests that repulsive interactions among protein subunits increase with $|Z|$, the absolute magnitude of protein charge, regardless of sign.

The principal effect of repulsive interactions is reduction in or reversal of aggregation rates. Thus, Figure 1 corresponds to association in the $\mathrm{pH}$ range from 7 to 5 and dissociation of those aggregates below $\mathrm{pH}$ 5. As noted above, an equilibrium is attained when the two rates are equal, corresponding to the maxima. The symmetry around $\mathrm{pH}_{\max }$ is quite different from the low ionic-strength aggregation of BLG, ${ }^{49}$ in which distinctly asymmetric high- and low-pH regions correspond to different mechanisms and different rates of aggregation and disaggregation; thus, a large hysteresis is observed for sequential addition of acid and base. In the present case, the mechanisms of association and dissociation also need not be identical and may have different $\mathrm{pH}$ dependences, but the hysteresis is small, giving the appearance of reversibility (see Supporting Information).

Much as the condition of $\left(\mathrm{d} \tau^{\prime} / \mathrm{dpH}\right)=0$ corresponds to a steady state, the maximum in this term at the inflection point (maximum slope) at $\mathrm{pH} 5.5$ is as the $\mathrm{pH}$ of maximum 


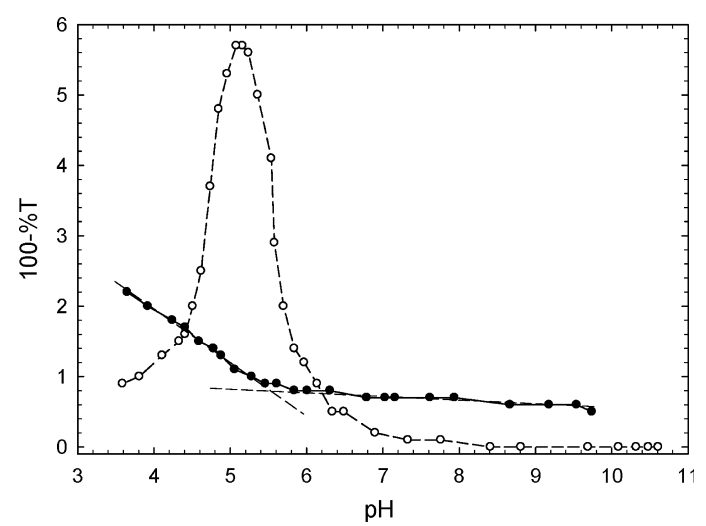

Figure 3. Turbidimetric titration of $0.1 \mathrm{~g} / \mathrm{L}$ insulin alone $(O)$ and with $0.01 \mathrm{~g} / \mathrm{L}$ heparin $(\bullet)$; both in $10 \mathrm{mM} \mathrm{NaCl}$. The intersection of the two broken lines may correspond to the transition from insulin-heparin intrapolymer complexes to soluble aggregates formed by association of intrapolymer complexes at $\mathrm{pH}<5.4$.

aggregation rate. This corresponds to the condition at which the difference between aggregation and disaggregation rates attains its maximum value.

Aggregation of insulin under mild conditions has typically been treated from the standpoint of pure equilibrium. ${ }^{15}$ To validate kinetic contributions as proposed in the preceding paragraph, stopped flow measurements were made at $0.1 \mathrm{~g} / \mathrm{L}$ insulin, and ionic strengths from $2-100 \mathrm{mM}$, all at $\mathrm{pH} 5.5$, the condition at which addition of $\mathrm{HCl}$ generates the maximum slope in Figure 1. As seen in Figure 2, the $10 \mathrm{mM}$ solution had the highest rate of aggregation as expected. The very low aggregation rate of $5 \mathrm{mM}$ is in agreement with the turbidimetric titration data of Figure 1, in which the curve has a slope (and, therefore,

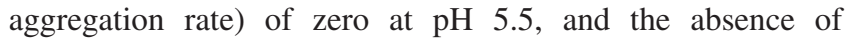
aggregation at $100 \mathrm{mM}$ is consistent with the observation that little to no aggregation at this $\mathrm{pH}$ is seen in turbidimetric titrations at $I>30 \mathrm{mM}$ (data not shown). The change in the time dependence of the turbidity after the first minute may suggest two different aggregation mechanisms, most clearly evident in the data for $2 \mathrm{mM} \mathrm{NaCl}$, but also possible at higher ionic strengths. The crossing of the $2 \mathrm{mM}$ and $10 \mathrm{mM}$ curves would be consistent with two processes with different ionic strength dependences. Similar effects have been observed for the near-isoelectric aggregation of BLG. ${ }^{49}$

When $0.01 \mathrm{~g} / \mathrm{L}$ heparin was incorporated into the system prior to titration with $\mathrm{HCl}$ (Figure 3), no change in turbidity was observed until around $\mathrm{pH} 5$, although the value of $\tau^{\prime}$ greater than that of the insulin dimer (heparin-free solution at $\mathrm{pH}>7$ ) indicates the formation of a heparin-insulin complex. The existence of this complex at $\mathrm{pH}>\mathrm{pI}$ is presumably an example of binding "on the wrong side of pI", now generally recognized as a consequence of protein charge anisotropy. ${ }^{50}$ The rather linear increase in turbidity as $\mathrm{pH}$ descended below $\mathrm{pI}$ corresponds to progressively stronger heparin-protein interaction, possibly leading to association of primary intrapolyanion complexes as they approach charge neutrality. ${ }^{51}$ Designating the initial formation of soluble complexes as " $\mathrm{pH}_{\mathrm{c}}$ " and eventual phase separation condition as " $\mathrm{pH}_{\varphi}$ "52-54 we see $\mathrm{pH}_{\mathrm{c}}>\mathrm{pI}+1$, and $\mathrm{pH}_{\varphi}<\mathrm{pI}-2$. For heparin and bovine serum albumin in 30 $\mathrm{mM} \mathrm{NaCl}$, we observed $\mathrm{pH}_{\mathrm{c}}=\mathrm{pI}+2$ and $\mathrm{pH}_{\varphi} \approx \mathrm{pI}^{40}$

The results of Figure 3 suggested that heparin might reverse insulin aggregation as well as inhibit it. Therefore, insulin was titrated to $\mathrm{pH} 5.2$, and allowed to reach a turbidity somewhat higher than that attained at this $\mathrm{pH}$ in Figure 3. To this solution of aggregated insulin, heparin was added rapidly to achieve a

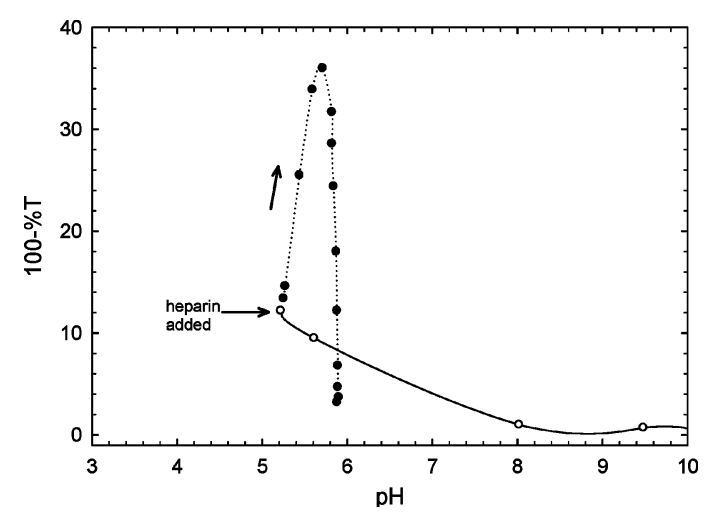

Figure 4. Insulin solution $0.1 \mathrm{~g} / \mathrm{L}$ brought to $\mathrm{pH} 5.2(\bigcirc), 1 \mathrm{~g} / \mathrm{L}$ heparin was added to bring the heparin concentration to $0.01 \mathrm{~g} / \mathrm{L}(\bullet)$ and aggregates dissociated after about $40 \mathrm{~min}$. During this period, the $\mathrm{pH}$ increased from 5.2 to 5.8 .

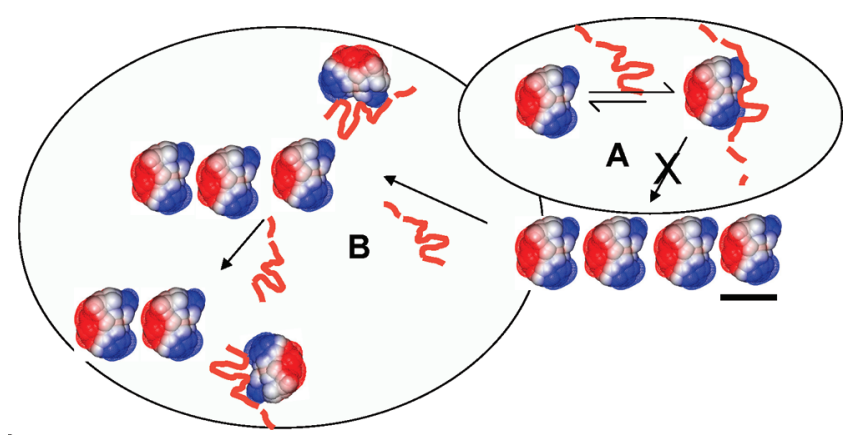

Figure 5. Schematic demonstrating inhibition of linear aggregate formation $(A)$ and dissociation of aggregates $(B)$ as a result of heparin binding (possible intermediate heparin-induced flocculation of insulin aggregates not shown). Length bar is $3 \mathrm{~nm}$. Potential contours of $+0.5 \mathrm{kT}$ (blue) and $-0.5 \mathrm{kT}$ (red) for the insulin dimer at $\mathrm{pH} 5.5$ and $I=10 \mathrm{mM}$; a portion of heparin chain represented by red line.

concentration of $0.01 \mathrm{~g} / \mathrm{L}$, with the results shown in Figure 4. The rapid initial increase in turbidity indicated that heparin was coagulating insulin aggregate particles. This interaction caused an increase in solution $\mathrm{pH}$ that was not observed when aggregated insulin was monitored without heparin for $45 \mathrm{~min}$. Turbidity then gradually diminished and after $40 \mathrm{~min}$ the transmittance reached $97 \%$, nearly that of the soluble complex, indicating that heparin was able to dissociate insulin aggregate particles through formation of soluble complexes.

\section{Discussion}

Ionic Strength Dependence of Insulin Aggregation. The low values of turbidity and the low initial rate of turbidity increase at ionic strength $\geq 30 \mathrm{mM}$ in Figures 1 and 2, respectively, indicate salt suppression of aggregation, similar to that reported by us for BLG at $5<I<100 \mathrm{mM}$, at $\mathrm{pH}$ near pI. ${ }^{49}$ Because hydrophobic interactions increase with added salt ${ }^{55-57}$ and hydrogen bonds are not influenced by ionic strength, aggregation here must be attributed to electrostatic interactions arising from charge anisotropy. This is readily visualized in Figure 5 (see below) in which $+0.5 \mathrm{kT}$ (blue) and $-0.5 \mathrm{kT}$ (red) potential contours are displayed for the insulin dimer at $\mathrm{pH} 5.5$ and $I=10 \mathrm{mM}$ (conditions of maximum aggregation). This dipolar charge anisotropy suggests linear multimerization of insulin, with distances of about $4 \mathrm{~nm}$ between the centers of mass of adjacent proteins. The reported equilibria among dimer, tetramer and hexamer (along with the possibility of higher multimers) for zinc-free insulin at moderate $\mathrm{pH}$ is 
consistent with this description. ${ }^{58}$ Maximum electrostatic attraction will occur when repulsive forces are screened but shorter-range attractive forces are not, i.e at a Debye length $\kappa^{-1}$ on the order of the protein diameter $d_{\mathrm{pr}}(3 \mathrm{~nm})$, corresponding to an ionic strength of about $I=10 \mathrm{mM}$ (see Figure 5 for representation of the electrostatic view of the insulin dimer). At larger values of $\kappa^{-1}(I=5$ and $3 \mathrm{mM})$, the maximum turbidity diminishes by a factor of 2 or 3 . The behavior at $I=$ $0.5 \mathrm{mM}$ appears anomalous, but at such low ionic strengths the contributions of protein to $I$ are no longer negligible and therefore not suitable for close interpretation.

It is interesting to note that, in contrast to the present case, the effect of ionic strength for electrostatically induced aggregation of BLG is monotonic, ${ }^{49}$ and that maximum aggregation rates are observed not at $\mathrm{pI}$ but at $\mathrm{pH}$ values 0.5 units below the isoelectric point. The mechanisms of aggregation are very different, with $\mathrm{Zn}$-free insulin at nonextreme $\mathrm{pH}$ conditions forming predominantly dimers, tetramers, hexamers, and higher order multimers, ${ }^{59}$ while BLG forms dimers in equilibrium with much larger aggregates. ${ }^{49}$ The possibility that these differences arise from the higher degree of charge asymmetry for BLG at $\mathrm{pH}$ near $\mathrm{pI}$ (a distinct positive domain coupled with a large and more diffuse negative domain, which leads to a tendency for highly nonlinear aggregation ${ }^{49}$ ) is certainly a hypothesis worth further examination.

The nonmonotonic ionic strength dependence of protein aggregation has been explained by Prausnitz and co-workers ${ }^{60}$ in terms of colloid asymmetric charge distributions. In such systems, salt may screen out (long-range) charge-charge repulsion at a lower ionic strength than that required to screen (short-range) dipole-dipole interactions, leading to maxima in the potential of mean force in the $10-100 \mathrm{mM}$ range. Similar nonmonotonic salt effects were observed by Seyrek ${ }^{61}$ et al. for the binding of polyelectrolytes to proteins with the same global charge sign, with maxima in the range of $10-40 \mathrm{mM}$. These ionic strengths corresponded to Debye lengths close to protein radii $r_{\mathrm{pr}}$, consistent with short-range attraction between the polyelectrolyte and an oppositely charged "patch" on the protein, in combination with longer-range repulsion between the polyelectrolyte and the distal (same-charge regions) of the protein. Maximum interaction at $\kappa^{-1} \approx r_{\mathrm{pr}}$ instead of $\kappa^{-1} \approx d_{\mathrm{pr}}$ might indicate that the distance between the protein center of mass and the bound polyelectrolyte residues is smaller than the distance between protein centers of mass in the aggregates described here.

The kinetics of aggregation are represented by the stoppedflow data of Figure 2. The condition of $I=10 \mathrm{mM}$ displays, as expected, the maximum initial rate, but interestingly also attains a limiting (equilibrium) value within one minute, which suggests stabilization of one particular aggregation state. Because the concentration here is much too low for the formation of the zinc-free hexamer, ${ }^{15}$ the results suggest a distribution of oligomers with mean lengths stabilized by a balance between electrostatic interprotein attractions that favor oligomerization and entropic effects in the opposite direction. In contrast, the data for $2 \mathrm{mM}$ indicate open-ended aggregation, with a transition to nearly linear behavior after 1 min (broken line). This, along with the crossing of these two curves, suggests a two-step aggregation process, in which the rate of the second step is dependent upon the end product of step 1. This is similar to the proposed two-step mechanism for heat-induced insulin aggregation, ${ }^{10}$ the second step involving further growth of the linear oligomers formed initially.
The interpretation put forward is consistent with the results of Kadima et al. who reported distribution of aggregation numbers ranging from $2-10$ under conditions of low protein net charge. ${ }^{15}$ Because those measurements were carried out at protein concentrations larger than ours by a factor of 20-100, we obtained the $\mathrm{pH}$-turbidity titration at $1 \mathrm{~g} / \mathrm{L}$ insulin in 10 $\mathrm{mM} \mathrm{NaCl}$ (not shown). While turbidities were an order-ofmagnitude larger than at $0.1 \mathrm{~g} / \mathrm{L}$ insulin, the $\mathrm{pH}$ values for the onset and reversal of aggregation were similar to those in Figure 1 , the principal difference being more rapid aggregation at $6.5<\mathrm{pH}<7$. The observation that the rate of disaggregation remained rapid regardless of a 10-fold increase in insulin concentration is more consistent with high turbidity due to an increase in the number of aggregates, as opposed to the formation of very large ones.

Effect of Heparin. Figure 3 demonstrates the suppression of insulin aggregation at $I=10 \mathrm{mM}$ in the presence of a 10 fold lower concentration of heparin, relative to the concentration of insulin. The symmetrical curve corresponding to aggregation and disaggregation of heparin-free insulin centered around $\mathrm{pH}$ $=\mathrm{pI}$ in Figure 1 is replaced by a region of constant turbidity at $\mathrm{pH}>\mathrm{pI}$, followed by a linear increase as $\mathrm{pH}$ decreases further. This corresponds to the onset of the formation of a net-negative soluble complex which, at $\mathrm{pH} \leq \mathrm{pI}$, approaches charge neutrality and is thus susceptible to higher-order aggregation, perhaps also reflecting a continued increase in the number of proteins bound per heparin chain. The inhibition of aggregation is a reflection of the binding of insulin to heparin, reducing the availability of the dimer for multimerization, with the positive domains of insulin now occupied by heparin as is illustrated in Figure 5A. The efficacy of heparin with a 10-fold molar excess of insulin (dimer), indicates a large number of proteins bound per polymer chain. At pH 6-7 in $10 \mathrm{mM} \mathrm{NaCl}$, heparin can bind about $n=$ 3 serum albumin proteins per chain, ${ }^{40,50}$ with BSA occupying on average 8 heparin disaccharides. With a hydrodynamic diameter about $40 \%$ that of BSA, insulin may occupy as few as three heparin disaccharides, corresponding to $n=8$. Because heparin is known to biofunctionally bind a number of insulinlike growth factors and their cognate proteins, protecting them from proteolysis, ${ }^{62}$ it is not surprising that some of the multitude of sulfated sequences found in heparin chains ${ }^{20}$ would have significant affinity for insulin, that is, binding constants larger than those for BSA. This could account for the efficacy of heparin at high dilution in the present case. This electrostatic description of the role of heparin is entirely consistent with the early report by Linhardt and Middaugh that the thermal stability of aFGF was enhanced by not only heparin but also "a surprising number of polyanions." 63

If the aggregation of insulin is subject to equilibrium, as indicated by the lack of significant hysteresis upon back-titration with $\mathrm{NaOH}$ for the system in Figure 1 (see Supporting Information), the binding of the insulin dimer to heparin should shift the equilibrium away from aggregate. Thus, heparin can reverse the aggregation of insulin, by the mechanism illustrated in Figure 5B. Figure 4 shows, however, that the first response to the addition of heparin is a large increase in turbidity which must arise from the flocculation of insulin aggregates by heparin (not shown in Figure 5B). Gradually, the system returns to a transmittance characteristic of scattering from soluble complexes. The simultaneous upward drift of $\mathrm{pH}$ is a result of the shift of amino acid $\mathrm{p} K_{\mathrm{a}} \mathrm{s}$ to higher values (lower acidity) when polyelectrolyte-binding influences the local activity coefficient of $\mathrm{H}^{+}, 53$ a phenomenon also know as "charge regulation". This shift could result in a larger effective pI for heparin-bound 
insulin, possibly raising the $\mathrm{pH}$ at which electrostatically neutral and hence associable heparin-insulin complexes can form. The causal role of the change in $\mathrm{pH}$ might be questioned, but the very large drop in turbidity at nearly constant $\mathrm{pH}=5.7$, indicates that disaggregation kinetics are being observed without the intermediating of $\mathrm{pH}$. The possibility that lower-MW heparin can effect disaggregation without aggregate flocculation is currently being explored.

\section{Conclusions}

The aggregation of insulin at room temperature near its isoelectric point is highly dependent upon both $\mathrm{pH}$ and ionic strength, suggesting that the driving force is electrostatic intermolecular attraction. The nonmonotonic ionic strength dependence of aggregation arises from the pronounced charge anisotropy of insulin. By binding to dimeric insulin at $\mathrm{pH}>6$, heparin prevents the bound insulin from participating in aggregation. These insulin-heparin complexes appear to be of lower energy than insulin aggregates, so the addition of heparin to insulin aggregates shifts the equilibrium back to soluble complexes. The behavior of low MW heparins of increasing importance as drugs is of particular interest, and it has even been suggested that a very low MW synthetic analog of heparin (fondaparinux) might alleviate the pathological formation of protein aggregates induced by standard heparin. ${ }^{64}$ The implications of the current findings for the physiologically significant interaction of heparan sulfate with insulin-like growth factors remain to be examined. Finally, optimal methods for structural and energetic characterization of aggregates and soluble complexes, including dynamic light scattering and frontal analysis continuous capillary electrophoresis, ${ }^{65}$ are clearly indicated for future studies.

Acknowledgment. We acknowledge support from Grant NSF CHE-0619039.

Supporting Information Available. Forward and reverse turbidity versus $\mathrm{pH}$ curves. This information is available free of charge via the Internet at http://pubs.acs.org.

\section{References and Notes}

(1) Shastry, B. S. Neurodegenerative disorders of protein aggregation. Neurochem. Int. 2003, 43, 1-7.

(2) Nettleton, E. J.; Tito, P.; Sunde, M.; Boushard, M.; Dobson, C. M.; Robinson, C. V. Characterization of the oligomeric states of insulin in self-assembly and amyloid fibril formation by mass spectrometry. Biophys. J. 2000, 79, 1053-1065.

(3) Nielsen, L.; Frokjaer, S.; Brange, J.; Uversky, N.; Fink, A. L. Probing the mechanism of insulin fibril formation with insulin mutants. Biochemistry 2001, 40, 8397-8409.

(4) Nielsen, L.; Khurana, R.; Coats, A.; Frokjaer, S.; Brange, J.; Vyas, S.; Uversky, V. N.; Fink, A. L. Effect of environmental factors on the kinetics of insulin fibril formation: Elucidation of the molecular mechanism. Biochemistry 2001, 40, 6036-6046.

(5) Jansen, R.; Dzwolak, W.; Winter, R. Amyloidogenic self-assembly of insulin aggregates probed by high resolution atomic force microscopy. Biophys. J. 2005, 88, 1344-1353.

(6) DeFelippis, M. R.; Chance, R. E.; Frank, B. H. Insulin self-association and the relationship to pharmacokinetics and pharmacodynamics. Crit. Rev. Ther. Drug Carrier Syst. 2001, 18, 201-264.

(7) Nielsen, L.; Frokjaer, S.; Carpenter, J. F.; Brange, J. Studies of the structure of insulin fibrils by fourier transform infrared (FTIR) spectroscopy and electron microscopy. J. Pharm. Sci. 2001, 90, 2937.

(8) Bohidar, H. B.; Geissler, E. Static and dynamic light scattering from dilute insulin solutions. Biopolymers 1984, 23, 2407-2417.
(9) Mauro, M.; Craparo, E. G.; Martorana, V.; Bulone, D.; San Biagio, P. L. Kinetics of insulin aggregation: Disentanglement of amyloid fibrillation form large-size cluster formation. Biophys. J. 2006, 90, 4585-4591.

(10) Dzwolak, W. Aggregation of bovine insulin probed by DSC/PPC calorimetry and FTIR spectroscopy. Biochemistry 2003, 42, 1134711355.

(11) Krebs, M. R. H.; Bromley, E. H. C.; Rogers, S. S.; Donald, A. M. The mechanism of amyloid spherulite formation by bovine insulin. Biophys. J. 2005, 88, 2013-2021.

(12) Dzwolak, W.; Ravindra, R.; Winter, R. Hydration and structure-the two sides of the insulin aggregation process. Phys. Chem. Chem. Phys. 2004, 6, 1938-1943.

(13) Brange, J.; Andersen, L.; Laursen, E. D.; Meyn, G. R. E. Toward understanding insulin fibrillation. J. Pharm. Sci. 1997, 86, 517-525.

(14) Gibson, T. J.; Murphy, R. M. Inhibition of insulin fibrilogenesis with targeted peptides. Protein Sci. 2006, 15, 1133-1141.

(15) Kadima, W.; Ogendal, L.; Bauer, R.; Kaarlsholm, N.; Brodersen, K.; Hansen, J. F.; Porting, P. The influence of ionic strength and $\mathrm{pH}$ on the aggregation properties of zinc-free insulin studied by static and dynamic laser-light scattering. Biopolymers 1993, 33, 1643-1657.

(16) Pocker, Y.; Biswas, S. B. Self-association of insulin and the role of hydrophobic bonding: A thermodynamic model of insulin dimerization. Biochemistry 1981, 20, 4354-4361.

(17) Banga, A. K. Therapeutic peptides and proteins: Formulation, processing, and delivery systems; CRC Press: Boca Raton, FL, 2006.

(18) Lord, R. S.; Gubensek, F.; Rupley, J. A. Insulin self-association. Spectrum changes and thermodynamics. Biochemistry 1973, 12, 43854392.

(19) Bryant, C.; Spencer, D. B.; Miller, A.; Bakaysa, D. L.; McCune, K. S.; Maple, S. R.; Pekar, A. H.; Brems, D. N. Acid stabilization of insulin. Biochemistry 1993, 32, 8075-8082.

(20) Conrad, H. E. Heparin-Binding Proteins; Academic Press: New York, 1998, Chapter 2.

(21) Mikhailov, D.; Young, H. C.; Linhardt, R. J.; Mayo, K. H. Heparin dodecasaccharide binding to platelet factor-4 and growth-related protein- $\alpha$. J. Biol. Chem. 1999, 274, 25317-25329.

(22) Bentolila, A.; Vlodavsky, I.; Haloun, C.; Domb, A. J. Synthesis and heparin-like biological activity of amino acid-based polymers. Polym. Adv. Technol. 2000, 11, 377-387.

(23) Gatti, G.; Casu, B. Studies on the conformation of heparin by ${ }^{1} \mathrm{H}$ and ${ }^{13}$ C NMR dpectroscopy. Macromolecules 1979, 12, 1001-1007.

(24) Calamai, M.; Kumita, J. R.; Mifsud, J.; Parrini, C.; Ramazzotti, M.; Ramponi, G.; Taddei, N.; Chiti, F.; Dobson, C. M. Nature and significance of the interactions between amyloid fibrils and biological polyelectrolytes. Biochemistry 2006, 45, 12806-12815.

(25) Raman, B.; Chatani, E.; Kihara, M.; Ban, T.; Sakai, M.; Hasegawa, K.; Naiki, H.; Rao, C. M.; Goto, Y. Critical balance of electrostatic and hydrophobic interactions is required for $\beta$-microglobulin amyloid fibril growth and stability. Biochemistry 2005, 44, 1288-1299.

(26) Castillo, G. M.; Lukito, W.; Wright, T. N.; Snow, A. D. The sulfate moieties of glycosaminoglycans are critical for the enhancement of beta-amyloid protein fibril formation. J. Neurochem. 1999, 72, 217220.

(27) Cohlberg, J. A.; Li, J.; Uversky, V. N.; Fink, A. L. Heparin and other glycosaminoglycans stimulate the formation of amyloid fibrils from $\alpha$-synuclein in vitro. Biochemistry 2002, 41, 1502-1511.

(28) Guzmán-Casado, M.; Garcia-Maria, M. M.; Sánchez-Ruiz, J. M.; Giménez-Gallego, G.; Parody-Morreale, A. Energetics of heparin binding to human acidic fibroblast growth factor. Biol. Macromol. 2002, 31, 45-54.

(29) Fan, H.; Li, H.; Zhang, M.; Middaugh, C. R. Effects of solutes on empirical phase diagrams of human fibroblast growth factor 1 . J. Pharm. Sci. 2007, 95, 1490-1503.

(30) Derrick, T.; G., A, O.; Vitharana, S. N.; Jones, L.; Rexroad, J. S., A.; Perkins, M.; Spitznagel, T. M.; Middaugh, C. R. Effect of polyanions on the structure and stability of repiferminTM (keratinocyte growth factor-2). J. Pharm. Sci. 2007, 96, 761-776.

(31) Zamiri, C.; Groves, M. J. Stabilization of somatropin by heparin. J. Pharm. Pharmacol. 2005, 57, 555-564.

(32) Wen, J.; Hsu, E.; Kenney, W. C.; Philo, J. S.; Morris, C. F.; Arakawa, T. Characterization of the keratinocyte growth factor binding to heparin and dextran sulfate. Arch. Biochem. Biophys. 1996, 332, 41-46.

(33) Chong, M. W.; Molnar, T. E.; McKean, R. E.; Spenlehauer, G. A. Stabilizers against heat-induced aggregation of RPR 11849, and acidic fibroblast growth factor (aFGF). Int. J. Pharm. 1998, 167, 25-36.

(34) Kajio, T.; Kawahara, K.; Kato, K. Stabilization of basic fibroblast growth factor with dextran sulfate. FEBS Lett. 1992, 306, 243-246. 
(35) Galazka, V. B.; Smith, D.; Ledward, D. A.; Dickinson, E. Complexes of bovine serum albumin with sulphated polysaccharides: Effects of $\mathrm{pH}$, ionic strength, and high pressure treatment. Food Chem. 1999. 64, 303-310.

(36) Jones, L. S.; Yazzie, B.; Middaugh, C. R. Polyanions and the proteome. Mol. Cell. Proteomics 2004, 3, 746-768.

(37) Guo, X.; Condra, M.; Kimura, K.; Berth, G.; Dautzenberg, H.; Dubin, P. L. Determination of molecular weight of heparin by size exclusion chromatography with universal calibration. Anal. Biochem. 2003, 312, 33-39.

(38) Lin, M.; Larive, C. K. Detection of insulin aggregates with pulsedfield gradient nuclear magnetic resonance. Anal. Biochem. 1995, 229, 214-220.

(39) Tanford, C.; Kirkwood, J. G. Theory of protein titration curves. I. General equations for impenetrable spheres. J. Am. Chem. Soc. 1957, 79, 5333-5339.

(40) Hattori, T.; Kimura, K.; Seyrek, E.; Dubin, P. L. Binding of bovine serum albumin to heparin determined by turbidimetric titration and frontal analysis continuous capillary electrophoresis. Anal. Biochem. 2001, 295, 158-167.

(41) Tanford, C.; Epstein, J. The physical chemistry of insulin. I. Hydrogen ion titration curve of zinc-free insulin. J. Am. Chem. Soc. 1954, 76, 2163-2169.

(42) Edsall, J.; Wyman, J. Biophysical Chemistry, Academic Press: New York, NY, 1958.

(43) Winzor, D. J. Determination of the net charge (valence) of a protein A fundamental but elusive parameter. Anal. Biochem. 2004, 325, 1 20.

(44) Allahyarov, E.; Lowen, H.; Hansen, J. P.; Louis, A. A. Nonmonotonic variation with salt concentration of the second virial coefficient in protein solutions. Phys. Rev. E 2003, 67, 051404.

(45) Broide, M. L.; Tominc, T. M.; Saxowsky, M. D. Using phase transitions to investigate the effect of salts on protein interactions. Phys. Rev. E 1996, 53, 6325-6335.

(46) Petsev, D. N.; Vekilov, P. G. Evidence for non-DLVO hydration interactions in solutions of the protein apoferritin. Phys. Rev. Lett. 2000, 84, 1339-1342.

(47) Taratuta, V. G.; Holschbach, A.; Thurston, G. M.; Blankschtein, D.; Benedek, G. B. Liquid-liquid phase separation of aqueous lysozyme solutions: Effects of $\mathrm{pH}$ and salt identity. J. Phys. Chem. 1990, 94, 2140-2144.

(48) Curtis, R. A.; Ulrich, J.; Montaser, A.; Prausnitz, J. M.; Blanch, H. W. Protein-protein interactions in concentrated electrolyte solutionsHofmeister-series effects. Biotechnol. Bioeng. 2002, 79, 367-380.

(49) Majhi, P.; Ganta, R.; Vanam, R.; Seyrek, E.; Giger, K.; Dubin, P. Electrostatically driven protein aggregation: $\beta$-Lactoglobulin at low ionic strength. Langmuir 2006, 22, 9150.
(50) Dubin, P. L.; Park, J. M.; Muhoberac, B. B.; Xia, J. Effects of protein charge heterogeneity in protein-polyelectrolyte complexation. Macromolecules 1992, 25, 290-295.

(51) Tsuboi, A.; Izumi, T.; Hirata, M.; Xia, J.; Dubin, P. L.; Kokufuta, E. Complexation of proteins with a strong polyanion in an aqueous saltfree system. Langmuir 1996, 12, 6295-6303.

(52) Weinbreck, F.; Nieuwenhuijse, H.; Robijn, G. W.; de Kruif, C. G. Complex formation of whey proteins: Exocellular polysaccharide EPS B40. Langmuir 2003, 19, 9404-9410.

(53) Wen, Y.-p.; Dubin, P. L. Potentiometric studies of the interaction of bovine serum albumin and poly(dimethyldiallylammonium chloride). Macromolecules 1997, 30, 7856-7861.

(54) Xia, J.; Dubin, P. L.; Kim, Y.; Muhoberac, B. B.; Klimkowski, V. J. Electrophoretic and quasi-elastic light scattering of soluble proteinpolyelectrolyte complexes. J. Phys. Chem. 1993, 97, 4528-4534.

(55) Borejdo, J.; Linder, S.; Werber, M. M. Hydrophobic interaction chromatography of myosin fragments: Potential use in purification. Arch. Biochem. Biophys. 1984, 231, 193-201.

(56) Stahlberg, J.; Jonsson, B.; Horvath, C. Theory for electrostatic interaction chromatography of proteins. Anal. Chem. 1991, 63, 18671874.

(57) Tsumoto, K. Arginine improves protein elution in hydrophobic interaction chromatography: The cases of human interleukin-6 and activin-A. J. Chromatogr., A 2007, 1154, 81-86.

(58) Jeffrey, P. D.; Coates, J. H. An equilibrium ultracentrifuge study of the self-association of bovine insulin. Biochemistry 1966, 5, 489-498.

(59) Pekar, H.; Frank, B. H. Conformation of proinsulin. A comparison of insulin and proinsulin self-association at neutral $\mathrm{pH}$. Biochemistry 1972, 11, 4013-4016.

(60) Tavares, F. W.; Bratko, D.; Striolo, A.; Blanch, H. W.; Prausnitz, J. M. Phase behavior of aqueous solutions containing dipolar proteins from second-order perturbation theory. J. Chem. Phys. 2004, 120, 98599869.

(61) Seyrek, E.; Dubin, P. L.; Tribet, C.; Gamble, E. A. Ionic strength dependence of protein-polyelectrolyte interactions. Biomacromolecules 2003, 4, 273-282.

(62) Arai, T.; Arai, A.; Busby, W. H.; Clemmons, D. R. Glycosaminoglycans inhibit degradation of insulin-like growth factor-finding protein5. Endocrinology 1994, 135, 2358-2363.

(63) Volkin, D. B.; Tsai, P. K.; Dabora, J. M.; Gress, J. O.; Burke, C. J.; Linhardt, R. J.; Middaugh, C. R. Physical stabilization of acidic firbroblast growth factor by polyanions. Arch. Biochem. Biophys. 1993, 300, 30-41.

(64) Kuo, K. H. M.; Kovacs, M. J. Fondaparinux: A potential new therapy for HIT. Hematology 2005, 10, 271-275.

(65) Gao, Y.; Dubin, P. L.; Muhoberac, B. B. Measurement of the binding of proteins to polyelectrolytes by frontal analysis continuous capillary electrophoresis. Anal. Chem. 1997, 69, 2945-2951.

BM8002557 